\title{
A fronteira México-Estados Unidos: entre o sonho e o pesadelo - as experiências de e/imigrantes em viagens não-autorizadas no mundo global ${ }^{*}$
}

\begin{abstract}
Gláucia de Oliveira Assis ${ }^{*}$
Resumo

Este artigo discute as experiências de homens e mulheres brasileiros, que tentam cruzar a fronteira México-Estados Unidos em viagens não-autorizadas no mundo global. São viajantes clandestinos que, com a ajuda dos coiotes, tentam entrar na "América". Na produção sobre tráfico de pessoas e "contrabando" ou tráfico de migrantes (smuggling), as questões relativas a gênero tendem a ser tratadas considerando-se que os homens brasileiros estão predominantemente vinculados ao tráfico de migrantes, enquanto as mulheres são vítimas de tráfico de pessoas para exploração sexual. Neste texto mostro que homens $e$ mulheres estão envolvidos no tráfico de migrantes e ambos enfrentam os riscos, a aventura ou desventura de cruzar a fronteira ou de ser deportado.
\end{abstract}

Palauras-chave: Tráfico de Migrantes, Gênero, Emigrantes Brasileiros, Fronteira México-Estados Unidos.

\footnotetext{
* Recebido para publicação em setembro de 2008, aceito outubro de 2008. A primeira versão deste texto foi apresentada na $26^{a}$ Reunião Brasileira de Antropologia (Porto Alegre, 2008) e no Seminário "Gênero no Tráfico de Pessoas" (Pagu/Unicamp, 2008). Agradeço os comentários e críticas realizadas nestes dois fóruns.

*** Doutora em Ciências Sociais pela Unicamp; Professora do Centro de Ciências Humanas e da Educação - Universidade do Estado de Santa Catarina - FAED/ UDESC.galssis@hotmail.com
} 
A fronteira México-Estados Unidos

The Mexico-United States Border:

Between the Dream and the Nightmare - the Experiences of Emigrants/Immigrants in Non-Authorized Trips in the Global World

\begin{abstract}
This article discusses the experiences of Brazilian men and women who try to cross the México-United States border in nonauthorized trips in the global world. They are illegal travelers who, with the coyotes' help (immigrant smugglers), try to get into "America". In the literature, questions concerning gender tend to be treated by taking for granted that the Brazilian men are predominantly linked to migrant smuggling, while the women are victims of trafficking for sexual exploitation. The aim of this text is to demonstrate that both men and women are involved in migrant smuggling and both face the risks, the fortune or misfortune of crossing the border or being deported.
\end{abstract}

Key Words: Gender, Migrant Smuggling, Brazilian Immigrants, Mexico-United States Border. 
Gláucia de Oliveira Assis

\section{Introdução}

No final do século $\mathrm{XX}$, a ampliação da circulação de trabalhadores migrantes $e$, nesse quadro, a feminização da migração, com a participação expressiva de mulheres, depara-se com políticas migratórias cada vez mais restritivas. Desse modo, a despeito da circulação de informação e de pessoas, bem como do barateamento dos transportes que permite a compressão do espaço pelo tempo, nem todos os cidadãos inserem-se igualmente no mundo globalizado. Notícias e relatos de imigrantes mortos na fronteira do México com os Estados Unidos e em barcos ou caminhões que tentam chegar à Europa oferecem um quadro dramático do que é tentar circular no mundo globalizado quando se é migrante indocumentado. No final do século $\mathrm{XX}$, e principalmente após os atentados de 11 de setembro de 2001, ocorreu uma intensificação dos sistemas de vigilância e controle nas fronteiras, o que tem contribuído para o aumento do smuggling, tráfico de imigrantes, pois homens e mulheres migrantes buscam estratégias para conseguir entrar nos países para os quais desejam migrar em busca de trabalho e de melhores condições de vida.

Na produção sobre tráfico de pessoas e "contrabando" ou tráfico de migrantes (smuggling), as questões relativas a gênero tendem a ser tratadas considerando-se que os homens brasileiros estão predominantemente vinculados ao tráfico de migrantes, enquanto as mulheres são vítimas de tráfico de pessoas para exploração sexual (Piscitelli, 2007; Kempadoo, 2005; Venzon, 2008). Neste artigo, mostro que homens e mulheres estão envolvidos no tráfico de migrantes e ambos enfrentam os riscos, a aventura ou desventura de cruzar a fronteira ou ser deportado.

Os dados para este artigo são provenientes de entrevistas realizadas durante minha tese de doutorado com pessoas que cruzaram a fronteira, cujas travessias eram narradas como aventuras, quando bem-sucedidas, ou como narrativas de 
A fronteira México-Estados Unidos

deportação que revelam a frustração de não conseguir entrar (Assis, 2004). Essas entrevistas foram realizadas em Governador Valadares em 2006, com uma migrante deportada e uma mãe que narrou a travessia do filho e da nora pela fronteira do México. Destaco que, nos estudos recentes de emigração de brasileiros, há relatos de deportação e travessia da fronteira nos trabalhos de Campos (2008), Siqueira (2006) e Santos (2007, 2006), que apresentam diferentes faces da travessia e demonstram a relevância de analisar a questão do tráfico de migrantes (smuggling) na migração contemporânea.

Quando as pessoas desejam cruzar as fronteiras para trabalhar em outros países, a criminalização que recai sobre o contrabando de imigrantes torna a questão bastante complexa, pois a noção de ajuda é muito forte entre os que desejam migrar. As pessoas nos países de origem confiam naqueles que, em sua cidade, vão ajudar a migrar: são os conterrâneos, vizinhos, parentes ou amigos que fornecem a informação, emprestam o dinheiro, ajudam a organizar o projeto de cruzar a fronteira $e$ vivem juntos a expectativa de chegada no destino.

$\mathrm{O}$ foco deste trabalho, portanto, não serão as leis que regulamentam a imigração, mas as vivências das pessoas que passaram por essa experiência de maneira ilegal. Relato aqui experiências de travessia da fronteira consideradas pelos emigrantes como bem-sucedidas e experiências frustradas, analisando como homens e mulheres situam-se em relação a essa experiência. Nos relatos, em geral, os emigrantes não se percebem como "contrabandeados" $e$, portanto, criminosos. Eles querem apenas pagar para poder cruzar a fronteira $e$, por isso, não se vêem como cometendo um crime. Querem apenas realizar o projeto migratório: trabalhar, juntar dinheiro e retornar ao país de origem.

Nesse ponto, é importante notar que, nas disposições legais internacionais, o smuggling refere-se ao "contrabando" de migrantes. No entanto, na literatura brasileira, o contrabando de migrantes tem sido traduzido como "tráfico de migrantes", o que 
conduz a confusões entre tráfico de pessoas e tráfico de migrantes. O Protocolo de Palermo definiu tráfico de pessoas como um crime que viola os direitos humanos de vítimas, pessoas submetidas a deslocamentos para serem exploradas, na forma de trabalho forçado e servidão em qualquer atividade. As pessoas envolvidas no tráfico de migrantes, que entram clandestinamente e cruzam fronteiras sem a devida documentação ou com documentos falsos, não são, porém, considerados como vítimas, mas como cometendo um crime contra o Estado. Na definição do Protocolo de Palermo, elas não são incluídas na categoria de tráfico de pessoas, mas na de contrabando ou tráfico de migrantes.

O Protocolo Adicional à Convenção das Nações Unidas contra o crime organizado transnacional relativo ao tráfico de migrantes por via terrestre, marítima e aérea, assinado pelo governo brasileiro em 2000 e ratificado em 2004, em seu artigo $3^{\circ}$, estabelece que:

a) a expressão tráfico de migrantes significa a promoção, com o objetivo de obter, de maneira direta ou indireta, beneficio financeiro ou outro benefício material, de entrada ilegal de uma pessoa numa parte do qual essa pessoa não seja nacional ou residente permanente;

b) a expressão "entrada ilegal" significa a passagem de fronteiras sem preencher os requisitos necessários para a entrada legal no Estado de acolhimento;

c) a expressão "documento de viagem fraudulento" significa qualquer documento de viagem ou de identificação: (i) que tenha sido falsificado ou adulterado de forma substancial por uma pessoa ou entidade que não esteja legalmente autorizada a fazer ou emitir documentos de viagem ou de identidade em nome de um Estado; ou (ii) que tenho sido emitido ou obtido de forma irregular, através de falsas declarações, corrupção ou coação ou qualquer outro meio ilícito; ou (iii) que seja utilizado por uma pessoa que não seja seu titular legítimo. 
A fronteira México-Estados Unidos

Assim, o smuggling apresenta uma diferença importante: enquanto no Protocolo de Palermo, sobre o tráfico de pessoas, o crime é contra os traficados, ou seja, estes são vítimas, no caso do "tráfico de migrantes", os migrantes que pagam a agenciadores, coiotes, amigos ou parentes são tão criminosos quanto aqueles para quem tiveram de pagar pela travessia. Nesse caso, há uma criminalização também do migrante, e não apenas de quem recebeu para fazer a travessia ou produziu um documento falso para a entrada em país estrangeiro. Conforme tem sido observado em vários documentos das Nações Unidas e em pesquisas realizadas no Brasil, no caso do tráfico de migrantes, a principal fonte de recursos são os valores pagos pelos migrantes, e esse tráfico tem uma característica transnacional, pois envolve cruzar fronteiras nacionais sem a devida documentação.

Esta apresentação não pretende relativizar o tráfico de migrantes. Reconhecendo a dura realidade que é cruzar as fronteiras e os riscos envolvidos, procuro trazer para o debate por que razões, a despeito desses riscos, as pessoas ainda tentam fazer essa travessia e que tipo de agência utilizam. Levando em conta as percepções das pessoas entrevistadas, fica claro que elas querem apenas "cruzar a fronteira" e não se vêem como cometendo um crime, mas apenas utilizando uma estratégia para cruzar a fronteira e realizar o sonho de "fazer a América".

Portanto, a questão do tráfico de migrantes deve ser pensada em articulação ao aumento da vigilância nas fronteiras dos países que mais recebem emigrantes. Tal vigilância tem levado ao aumento de deportações na Europa e nos Estados Unidos e culminou no retorno de exigência de visto de entrada de brasileiros para viagem ao México. 
Gláucia de Oliveira Assis

\section{Medidas restritivas contra a migração no contexto da "guerra contra o terror": o caso dos brasileiros barrados na fronteira do México}

A política imigratória muitas vezes é contraditória com as representações acerca da "América" como terra de oportunidades. Rossana Reis (2003), analisando comparativamente a política migratória estadunidense e francesa, demonstra que, ao longo do século XX, apesar da difusão dessa ideologia dos Estados Unidos como terra de oportunidades, mesmo no período de maior migração para esse país - entre o final do século XIX e o início de século $\mathrm{XX}-$, a política estadunidense de imigração estabelecia uma série leis restritivas aos imigrantes que eram selecionados segundo critérios religiosos e raciais. A autora ressalta também que, se até meados do século $\mathrm{XX}$ a discussão sobre a imigração girava em torno do eixo nativismo/religião civil, a partir do final do século $\mathrm{XX}$, num movimento que só tende a se acentuar depois dos atentados do dia 11 de setembro de 2001, o eixo principal da política de imigração parece ser direitos humanos/segurança nacional.

A preocupação com a segurança nacional pós-atentados parece ter colocado em xeque um dos princípios considerados fundamentais da constituição estadounidense e do governo republicano - a idéia de "liberdade". Como resposta aos ataques, foi declarada uma "guerra contra o terror", que se traduziu, entre outras medidas, em uma política migratória muito mais restritiva. Segundo Chomsky (2001), "guerra contra o terrorismo" é uma denominação genérica, constituindo-se mais em uma forma de propaganda, a não ser que a guerra realmente investisse contra o terrorismo. No entanto, o que se viu na seqüência de tal denominação foi a utilização desse termo para invadir países considerados "terroristas", como o Afeganistão e o Iraque - o que não é nosso objetivo discutir aqui - e uma mudança na política de concessão de vistos e de controle ou patrulhamento das fronteiras. 
A fronteira México-Estados Unidos

Segundo Yaler-Loher, Papademetiou e Cooper (2005), esse maior controle traduziu-se na tentativa de tecer uma rede de políticas que previnam a entrada de pessoas consideradas perigosas no espaço norte-americano a partir de três atividades profundamente entrelaçadas. As três medidas ${ }^{1}$ visam a tornar a homeland estadunidense mais segura do que antes dos ataques de 11 de setembro. Esse conjunto de medidas contribuiu, portanto, para criminalizar a migração internacional e, conseqüentemente, aqueles que tentam cruzar as fronteiras passam a ser tratados com mais rigor, desconfiança, como ameaça e perigo - os migrantes, estrangeiros e minorias étnicas - tornam-se suspeitos e são tratados como ameaça à segurança nacional o que se traduz em maior rigor na concessão de vistos, no aumento das prisões $e$ deportações (Póvoa Neto, 2005).

O endurecimento na concessão de vistos, a partir de 2001, tornou cada vez mais difícil a mobilidade daqueles que desejavam realizar o projeto de "fazer a América" na terra da "liberdade" - e as notícias, como a que segue, revelam a face mais dramática dessa política restritiva:

1 Com relação à concessão de vistos, alterou-se o tempo de permanência autorizada para os vistos de turismo e negócio (B1 e B2) e intensificou-se o rigor na concessão de vistos para estudantes, medidas contidas nas leis USA Patriot Act e Enhanced Border Security and Visa Entry Reform Act, promulgadas em 2002 (Santos, 2006). Outra medida tomada para todos os homens e mulheres com idade entre 16 e 45 anos, foi a solicitação do preenchimento de formulário com informações mais detalhadas sobre filiações políticas, educacionais, religiosas ou trabalhistas e um histórico mais detalhado da viagem (formulário DS-157). A partir de maio de 2003, os consulados estadunidenses passaram a entrevistar todos os candidatos a visto com idade inferior a 14 anos até de 79 anos, com poucas exceções (diplomatas e funcionários de certas organizações profissionais) (Yaler-Loher, Papademetiou e Cooper 2005). Com relação à chegada no país, outras medidas foram tomadas nas inspeções na fronteiras, como o programa "One face at the border", que tem combinado inspeções da imigração, alfândega e departamento de agricultura. Os oficiais recebem agora treinamento anti-terrorismo. Todos os viajantes que chegam aos aeroportos são submetidos ao US-Visit, que implica que certos viajantes (dentre eles os brasileiros) sejam cadastrados através de suas digitais e de sua fotografia. 
Gláucia de Oliveira Assis

No ano passado, aproximadamente 800 pessoas morreram na tentativa de atravessar o deserto do México e entrar nos Estados Unidos. Uma delas era Magda Gomes, brasileira (Jornal Nacional, 28/08/2003).

A notícia, veiculada no Jornal Nacional em agosto de 2003, revela um "outro lado" do projeto migratório: a migração através da fronteira com o México. A maior parte dos presos brasileiros por cruzar a fronteira é constituída por homens, mas a notícia destacou o fim trágico de uma mulher. Ela conta com detalhes os perigos da travessia pelo deserto - o calor, o risco de ataque de cobras e escorpiões - e enfatiza que aqueles que correm mais riscos são as mulheres e as crianças. A notícia revela ainda que, embora em pequeno número, cresce o contingente de mulheres que se arrisca nessa empreitada, descrita quase exclusivamente como uma alternativa para os homens.

O aumento significativo de brasileiros presos tentando cruzar a fronteira do México revela uma das conseqüencias dos atentados de 11 de setembro para os imigrantes. Com um maior rigor na concessão de vistos por parte do governo americano, aqueles que procuram migrar em busca de melhores condições de vida encontram cada vez mais dificuldade para cruzar as fronteiras. No caso da migração para os Estados Unidos, os criciumenses partem com visto de turista ou com passaporte italiano (que não exige visto para entrar nesse país), que tem um tempo de permanência de, no máximo, seis meses e não permite que os "turistas" trabalhem. Os migrantes chegam com esse visto, começam a trabalhar e permanecem indocumentados no país. Assim, encontramos $86,9 \%$ dos migrantes em situação ilegal ou indocumentados e 13,1\% em situação legal (Assis, 2004).

Segundo dados apresentados por Santos $(2006,2007) \mathrm{em}$ janeiro de 2004, cerca de 200 brasileiros foram deportados dos Estados Unidos, dos quais 17 provenientes da região sul catarinense. Em janeiro de 2005, 301 migrantes foram deportados também dos Estados Unidos, 199 do estado de Minas Gerais e 
quatro de Santa Catarina. Eles revelam que a passagem pela fronteira com o México tornou-se parte constitutiva da experiência migratória para os Estados Unidos, pois expressa a materialidade da fronteira $e$ as redes acionadas para cruzá-la. Redes que se iniciam como redes locais passam a ser subordinadas a redes internacionais, que desenvolvem um complexo sistema para o tráfico ilegal de imigrantes (Santos, 2006:23).

"Passar pelo México" é a única alternativa que resta àqueles que não conseguem o visto de turista para entrar nos Estados Unidos e, por isso, recorrem à estratégia de atravessar a fronteira pagando a um "coiote". Os "coiotes" são, em geral, mexicanos que cobram muito caro para atravessar imigrantes clandestinamente do México para os Estados Unidos através da fronteira - num tráfico de migrantes que tem crescido à medida que crescem as medidas restritivas à migração. Durante o trabalho de campo em Criciúma e na região de Boston, ouvi vários relatos de imigrantes sobre a perigosa travessia, incluindo a passagem de mulheres e crianças.

Em um desses dos relatos, um taxista de Criciúma contou orgulhoso a travessia de seu genro com a filha e o neto através da fronteira. O genro foi para os Estados Unidos pelo México, pois não conseguiu visto para ir para os Estados Unidos; lá arrumou trabalho e dinheiro para voltar ao Brasil e buscar a mulher $e$ os dois filhos pequenos e, "de quebra", levou também o cunhado todos conseguiram passar pelas perigosas correntezas do Rio Bravo, inclusive as crianças, e estavam juntos nos Estados Unidos. A narrativa da travessia como aventura e como motivo de orgulho daqueles que conseguiram passar dissimula a idéia de tráfico de migrantes, esconde o perigo $e$ as mortes ocorridas no trajeto.

A passagem pela fronteira do México é um evento que marca as trajetórias de homens e mulheres migrantes. A maioria quer esquecer como chegou e apenas "fazer a América", mas as marcas são, muitas vezes, profundas: a violência dos coiotes, a dor das famílias que perderam seus filhos afogados ou perdidos no deserto, os casos de mulheres violentadas. Partindo dessas 
experiências, o filme A Fronteira, realizado na região de Boston em 2002 e dirigido por Roberto Carminati, filho de imigrantes brasileiros estabelecidos desde a década de 1970 na região, descreve a trajetória de dois migrantes e suas famílias, retratando aqueles que conseguiram "fazer a América", reconstruir a vida $e$ legalizar-se e aqueles que, não conseguindo a documentação, permanecem ilegais, não conseguem se estabelecer, perdem tudo ou quase tudo e têm de voltar para o Brasil.

Assim, o filme aborda uma questão que se torna cada vez mais importante para os migrantes, principalmente após os atentados de 11 de setembro de 2001: o status migratório. Embora a maioria da população migrante brasileira seja indocumentada (Sales, 1999), essa não era uma questão relevante para os imigrantes antes dos atentados de 11 de setembro, já que conseguiam trabalhar, dirigir, colocar os filhos na escola sem problemas, vivendo relativamente bem "sem os documentos" (social security, drive license e green card), o que Sales denominou como a legitimidade da condição clandestina.

Depois de setembro de 2001, passou a haver um maior controle não só das fronteiras e dos vistos, mas também dos imigrantes indocumentados que trabalham no mercado de trabalho secundário americano. Há uma maior exigência dos empregadores e das firmas em relação à documentação; as "batidas da migração" tornam-se mais freqüentes nos locais de trabalho, como lanchonetes, supermercados, firmas de construção civil e limpeza, ou em uma blitz policial, pois o policial, ao solicitar a carteira de motorista, já verifica se o documento é falsificado ou não e, conseqüentemente, descobre o status migratório do motorista, podendo deportá-lo. A integração das atividades de polícia com a imigração (INS), que não ocorria antes dos atentados, aumentou a sensação de insegurança entre os imigrantes indocumentados.

Esse sentimento também foi observado por Margolis (2003) durante os dias que se seguiram aos ataques, quando muitos brasileiros buscaram registrar seus filhos nascidos como 
A fronteira México-Estados Unidos

estadunidense nos consulados, visando assegurar aos mesmos a cidadania brasileira. Desse modo, na eventualidade de haver mais ataques, poderiam retornar para o Brasil com seus filhos. O sentimento de segurança, ao qual os brasileiros sempre se referiam como uma das principais vantagens de morar nos Estados Unidos, foi duramente atingido. Se nos primeiros meses pós-atentados existiam indicativos de que muitos brasileiros estavam retornando para o Brasil e que haveria uma diminuição da emigração para os Estados Unidos - tanto em relação ao temor de novos atentados quanto em relação ao maior rigor na fronteira $e$ às dificuldades de lá viver e trabalhar -, em meados de 2002 crescia novamente o afluxo de brasileiros, como demonstraram os dados de brasileiros presos na fronteira que permanecem em presídios de segurança máxima nos Estados Unidos.

Segundo os dados da Embaixada dos Estados Unidos, o índice de brasileiros presos nessa situação cresceu $787 \%$, passando de 350 prisões em 1992 para 3.105 em 2001. Entre 2002 e 2003, foram 5.242 (Folha de S.Paulo, 24/03/2002:8-9). Mais recentemente, em reação a esse aumento do número de brasileiros presos na fronteira, o governo mexicano anunciou que, a partir de 23 de outubro do corrente ano, será novamente exigido visto de entrada para os brasileiros que quiserem viajar para o México. Embora o governo mexicano negue, essa medida é resultado da pressão dos Estados Unidos sobre este país e visa a diminuir a entrada de brasileiros que atravessam o México (Diário Catarinense, 10/09/2005). A exigência de visto para entrada no México, medida tomada em 2005, diminuiu a entrada de brasileiros pela fronteira mexicana, mas também estimulou a procura de novas rotas de migração.

Os migrantes brasileiros que se encontravam em presídios estadunidenses aguardando a deportação são parte dos migrantes indesejados. Os imigrantes não se consideram criminosos, nem uma ameaça à segurança nacional; apenas queriam trabalhar em outro país e circular no mundo globalizado, mas são impedidos de entrar no país e, além disso, são tratados como criminosos. Essa é 
uma das conseqüências da política imigratória atual do governo norte-americano, que passou a ver esses indivíduos como ameaça à segurança nacional. Nessa perspectiva, Yudice (2002:176) afirma que o imigrante clandestino ou indocumentado, após o 11 de setembro de 2001, apresenta ambigüidade em relação ao risco de segurança, mas é necessário como mão-de-obra barata; por outro lado, torna-se motivo para inquietações, principalmente no que tange à sociedade denominada pós-disciplinar, na qual ocorre um aumento crescente de identidades culturais não mais vinculadas à escola, à igreja, etc.

Assim, o tráfico de migrantes torna-se uma questão muitas vezes ambígua. A discussão sobre o tema envolve tanto aqueles que querem defender os direitos dos migrantes à livre circulação, quanto os Estados interessados em estabelecer políticas que coíbam esse tipo de tráfico $e$, ao fazer isso, também regulem a migração indocumentada. Dessa forma, o smuggling ou tráfico de migrantes evidencia a inserção desigual e discriminatória de trabalhadores/as no mundo globalizado e ganha visibilidade social e política, inclusive com a instalação de uma CPMI no Congresso Nacional para analisar o tráfico de migrantes na fronteira com o México e promover um debate sobre a necessidade de políticas públicas para os emigrantes brasileiros.

\section{As experiências de travessia: entre o sonho e o pesadelo cruzando múltiplas fronteiras}

As fronteiras no mundo contemporâneo são apropriadas $e$ atravessadas de diferentes maneiras pelo capital, pelos viajantes, turistas e migrantes. Ao mesmo tempo em que comerciais de TV e propagandas anunciam seu fim - "um mundo sem fronteiras" -, estas são reafirmadas no sentido mais estreito nas tentativas de controle do policiamento do território e da população. Dessa forma, as fronteiras permanecem espaços de disputa, de litígio; os migrantes entram nesse território e, ao enfrentar o rígido esquema 
A fronteira México-Estados Unidos

de controle e vigilância com seus corpos sexualizados, racializados e generificados, se submetem aos riscos e à violência da travessia.

Como destaca Campos (2008), em que pese os esforços para uma compreensão pertinente da fronteira como espaço praticado da diluição ou mesmo embaçamento de diferenças, é também consistente o argumento de que, reconhecendo-se a transformação acelerada da idéia de Estado-Nação, insere-se essa metamorfose na ordem dos discursos sobre o rompimento da mesma, e o fluxo crescente não apenas de mercadorias, mas especialmente de pessoas, num cristalizado processo de transnacionalismo e globalização. Nesse sentido, os relatos a seguir evidenciam as estratégias das pessoas que são excluídas da possibilidade de obter visto para entrar nos Estados Unidos, para circular no mundo globalizado, e que se utilizam de outros agentes, não-legais, para conseguir se inserir nesse mundo.

O projeto era poder comprar um apartamento pra ele, um carro, e ajudar o pai na construção da casa na época. Só que ele foi pra lá e não fez nada disso. Segundo as más línguas, foi só festa. $\mathrm{O}$ que ele alega é que cada vez que tava acertando o passo acontecia alguma coisa que ele quebrava e não podia continuar, até que veio embora (Luciana, irmã de Celso; entrevista realizada em Criciúma, 2001).

Em sua primeira experiência migratória, Celso sempre se manteve em contato com o Brasil. Naquela época, em 1993, não havia TV a cabo brasileira, mas os imigrantes alugavam fitas com as notícias e as novelas. Segundo Celso, a tia e a prima alugavam as novelas e ele se interessava pelas notícias. Também circulavam revistas e jornais do Brasil, maneira pela qual ficava a par dos acontecimentos.

Quando voltou ao Brasil, não pensava que retornaria para os Estados Unidos, queria conseguir um trabalho e ficar. Nesse período, ele morou um tempo em São Paulo, onde ficou até agosto de 1997, e voltou a trabalhar como garçom. No final desse mesmo ano, já pensava em voltar para os Estados Unidos, mas 
regressou para Criciúma, pois a mãe estava com câncer, e ele resolveu ficar mais próximo da família. Conforme seu relato, quando a mãe morreu, a família sofreu uma desestruturação: todos ficaram muito tristes, o pai ficou deprimido, pois havia permanecido casado por 27 anos, e ainda tinha uma irmã doente. Celso permaneceu por um tempo em Criciúma, trabalhando em uma boate como garçom, depois passou alguns meses trabalhando em Fortaleza, no Ceará, com alguns amigos, mas retornou para sua cidade já decidido a voltar para a "América": "Então, eu comecei a pensar em vir, já não dormia direito, conversei com alguns amigos e disse: prepara aí, que eu já estou voltando" (Celso, 30 anos, entrevista realizada em dezembro de 2001).

O tio materno, que estava em Boston, mais uma vez arranjou o dinheiro para a viagem (US\$4.500,00) e o pai também contribuiu com parte do dinheiro. Novamente, Celso nem tentou o visto para os Estados Unidos. Segundo seu relato, no Consulado dos Estados Unidos, em São Paulo, não estavam sendo concedidos vistos para pessoas procedentes de Governador Valadares ou de Criciúma: "Você chega no Consulado, e eles já sabem de tudo". Em março de 2001, atravessando outra vez a fronteira do México, Celso partiu para a região de Boston.

A segunda travessia pelo México foi mais demorada e difícil, pois foram presos na fronteira; viajavam em sete pessoas, todos homens, o mais velho tinha 46 anos e o mais novo estava com 29 anos - era Celso. Todos eram conhecidos de Celso, à exceção de um, que, de acordo com ele, foi quem "deu a mancada" que quase acabou deportando todo mundo. Passaram por quatro países: saíram de Florianópolis para São Paulo, de São Paulo para Lima, no Peru, depois para o México e de lá para os Estados Unidos. 
A fronteira México-Estados Unidos

A rota ${ }^{2}$, segundo Celso, foi informada pelo pessoal de Criciúma. Até chegar à fronteira com o México foram sozinhos e lá contrataram os coiotes para ajudar na travessia. Celso e os companheiros de viagem não atravessaram pelo deserto, mas passaram por uma cidade caminhando na fronteira do estado americano do Texas com o México. Celso comenta que não era possível fazer a travessia sem os coiotes:

Eles sabem o caminho. Eles sabem onde tem sensor no chão, onde tem as cercas, então eles desviam. Eles são especialistas em fazer essa travessia. $O$ cara que me atravessou faz essa travessia há 25 anos. Eles a fazem em três pessoas. O que vai na frente é o batedor, vê se não tem policial, se está tudo certo. Depois vem o irmão dele com a gente mostrando o caminho e tem outro bem perto da rua, onde passam as viaturas comunicando por celular a movimentação dos policiais. Nós estávamos bem perto da casa do irmão dele quando apareceu uma viatura e nós tivemos de nos esconder no mato. Eles foram embora e a gente prosseguiu. (...) Cada um pagou US\$1.800,00 para o coiote nos deixar em Houston (Celso, 30 anos, entrevista realizada em dezembro de 2001).

\footnotetext{
${ }^{2}$ A rota que Celso relatou, na fronteira do Texas, é considerada a travessia mais cara e menos arriscada. Pode custar entre US\$7.500,00 e US\$ $10.000,00$. O tempo de viagem pode ser de até 15 dias. Os agenciadores de Criciúma relatam que saem em grupos pequenos: no mínimo dois e no máximo seis imigrantes. As etapas são as mesmas descritas por Celso. Segundo os migrantes e os agenciadores, o desafio maior é despistar os check points da imigração norteamericana, pois entre o hotel onde ficam hospedados e a vigilância policial há uma viagem de 40 minutos. Nessa parte da viagem, o grupo entra no mato durante a madrugada e caminha cerca de 12 quilômetros, voltando a encontrar o carro a cinco quilômetros do posto policial. Essa é considerada a parte mais difícil. O carro transporta os passageiros que pagam o restante da quantia nesse momento (50\%). A partir desse ponto são levados para Houston, Dallas ou San Antonio, de onde se dirigem para a região de Boston, que fica a cerca de 4.000 quilômetros dessas cidades.
} 
Celso relatou a dificuldade de passar a fronteira, a prisão, o suborno dos policiais para saírem sem ir para a corte e assim evitar a deportação. Em Houston, foram presos, mas conseguiram subornar a polícia e pegar um vôo para Monterrey. De lá alugaram um carro, pois estavam checando os passaportes no aeroporto e decidiram ir de carro para Washington, deixando dois dos integrantes do grupo. Após 13 dias de viagem, eles conseguiram chegar à região de Boston. Celso voltou para a mesma região porque tinha a família do tio materno morando lá. $\mathrm{O}$ amigo com quem viajou tinha um irmão que trabalhava em uma firma de pintura e que prometeu trabalho para eles na mesma firma assim que chegassem.

Quando Celso relatou sua segunda travessia pelo México, embora destacasse as dificuldades e o risco da deportação, observei que a narrativa evidenciava um certo orgulho de ter conseguido passar a fronteira, subornar a polícia, fazer parte da viagem de ônibus, de avião, alugar um carro e conseguir chegar. Como outros relatos que ouvi de travessias pelo México, a coragem $e$ a ousadia são aspectos considerados como distintivos $e$ valorizam a empreitada. É relatado também como uma forma masculina de migrar, pois os riscos da travessia - cruzar um rio a nado, caminhar pelo deserto seguindo coiotes - são considerados muito perigosos para as mulheres.

Segundo os imigrantes, elas são mais vulneráveis e correm o risco de sofrer abuso sexual por parte dos coiotes. Os relatos de travessia de mulheres não eram tão frequentes no final de 2001. Isso não quer dizer que não ocorriam - registrei, anteriormente, o caso de uma mulher que atravessou com o marido e os filhos -, porém é mais difícil encontrar mulheres fazendo a travessia sozinhas.

O projeto de Celso era fazer "um pé-de-meia" para voltar ao Brasil no final de 2003. Ele migrou desejando adquirir uma casa e um carro, mas atualmente seu sonho de consumo é mais baixo. Celso ainda ajuda a família no Brasil, manda dinheiro à irmã que ficou e paga a sua faculdade. Quando as irmãs falam em 
migrar, diz que elas têm de estudar no Brasil para conseguir uma oportunidade melhor: "Não adianta perder a juventude aqui $e$ voltar sem estudar", disse Celso.

Quando o entrevistei, ele estava trabalhando na pintura, conforme tinha planejado, ganhava entre US\$10,00 e US\$14,00 a hora, o que significava cerca de U\$S 500,00 por semana, embora no inverno o trabalho diminua bastante. $\mathrm{O}$ inglês melhorou, mas Celso ainda não aprendeu a escrever nem a ler em inglês. Ele ficou até agosto na empresa que o irmão do amigo tinha arranjado assim que chegou, mas em setembro mudou-se para outra companhia porque pagava melhor. Voltou a morar com o tio materno, que retornou ao Brasil por problemas de saúde. Porém, permaneceram na casa a prima, outros primos e um tio da prima com quem divide o apartamento. Conforme Celso, o tempo de trabalho costuma ser de 12 a 13 horas por dia - bastante pesado em sua opinião -, o que dificulta pegar um part time. Ele também reforça a construção da imagem do brasileiro como um povo trabalhador: "O brasileiro é muito mais trabalhador do que os outros imigrantes, mais inteligente. $\mathrm{Na}$ área de construção civil, tudo o que o brasileiro faz é melhor" (Celso, 30 anos, entrevista realizada em dezembro de 2001).

A vida de Celso é marcada pelo trabalho diário na construção civil, mas, às vezes, entre uma obra e outra, ficava um tempo parado, sem trabalhar. Apesar de ter carro, a carteira estava vencida e como não tinha social security verdadeiro, não havia conseguido renová-la ainda, então, seu amigo sempre dirigia. Como outros imigrantes, Celso também é indocumentado; porém, quando perguntei se tinha interesse em legalizar-se, ele disse que não queria porque pensava em retornar para o Brasil. Celso está nos Estados Unidos, mas não se integra/interessa pela sociedade estadunidense; não se relaciona com o povo de lá, a não ser no trabalho, nem se interessa em estudar inglês. Colocou uma antena da parabólica da Rede Globo para assistir os programas brasileiros. Aos sábados e aos domingos, assiste aos 
jogos do campeonato brasileiro e às notícias do Brasil pelo "Fantástico".

Durante toda a entrevista, e nas outras vezes em que nos encontramos, Celso destacou o desejo de retornar ao Brasil. A "América é lugar para trabalhar, mas não é lugar para viver", disse ele mais de uma vez. Seu relato demonstra que a inserção em uma nova sociedade implica cruzar várias fronteiras além da fronteira do México. As fronteiras culturais e simbólicas parecem colocá-lo diante de novas sociabilidades, atributos de gênero, etnia e classe que são mais difíceis de cruzar. Nesse processo, o aprendizado da língua, o uso das redes sociais disponíveis, bem como uma maior interação com a sociedade estadunidense, são importantes na ampliação do tempo de permanência $e$ na redefinição do projeto em relação ao retorno. Na sociedade de recepção, a despeito de encontrar as redes de parentes e amigos para recebê-lo, Celso encontra dificuldades para se estabelecer em termos financeiros e afetivos, conforme ressaltou em seu relato. Isso fica explícito em sua afirmação recorrente de que os Estados Unidos é um lugar para trabalhar, e não para viver, e também no desejo de voltar para o Brasil.

\section{A história de Maria: o rapto e a violência na travessia}

Maria Helena, natural de Governador Valadares, tentou emigrar para os Estados Unidos em 2005, aos 27 anos - cursava o ensino superior e era professora de ensino fundamental em uma escola particular na cidade. O projeto de Maria Helena era migrar para conseguir pagar as prestações atrasadas da faculdade e, assim, poder retirar seu diploma e depois comprar uma casa.

Ela é solteira e, na época, não tinha namorado. Em seu depoimento, afirma que nunca tinha pensado em migrar, mas uma amiga que morava nos Estados Unidos e estava em visita ao Brasil convenceu-a a tentar a vida nos Estados Unidos. O convite era para ir morar na casa da mãe da amiga, estabelecida há 26 
A fronteira México-Estados Unidos

anos na Flórida, que a acolheria, arrumando moradia e ajudando a arranjar o emprego.

Eu nunca tinha pensado em ir assim pra lá, sabe? É que você tem milhões de exemplos, mas é porque foi meu último ano de faculdade e eu tava formada, mas o último ano eu não terminei de pagar. Não consegui pagar, né? Aí... problema na faculdade, né? Não querem dividir, só querem dinheiro à vista, não tinha como arrumar dinheiro, aí eu tava desesperada, querendo meu diploma. E até hoje eu tô pra ter o meu diploma, que não tenho. Aí o motivo maior foi esse, eu conseguir, porque tenho vontade de estudar ainda mais. Conseguir ter um dinheiro a mais... Daí veio a vontade de querer ter uma casa também, mas o principal foi a minha faculdade. ${ }^{3}$

Ao tomar a decisão de partir para tentar a vida nos Estados Unidos, Maria Helena, assim como Celso nem tentou tirar o visto norte-americano. Há, nesse processo, uma auto-exclusão: Maria Helena afirma que nem tentou porque era natural de Governador Valadares e que era muito difícil conseguir o visto no consulado norte-americano. Assim, decide cruzar a fronteira do México com os Estados Unidos em setembro de 2005, aproveitando que ainda não estavam exigindo visto de entrada para o México.

Maria Helena procurou pessoas de seus contatos para realizar a travessia: o pai de um de seus ex-alunos a ajudou $e$ indicou-lhe a irmã, que era a cabeça, ou seja, que era a "cônsul". 4

${ }^{3}$ Entrevista realizada em Governador Valadares em 01/05/2007 por Gláucia de Oliveira Assis. O nome foi trocado por um nome fictício para preservar a identidade da imigrante.

${ }^{4}$ Cônsul é um termo utilizado pelos emigrantes para se referir às pessoas que agenciam a entrada nos Estados Unidos através da fronteira com o México. O termo é uma referência jocosa ao cargo diplomático e ao seu poder de permitir a entrada por meio do visto de turista. Em Governador Valadares, a cônsul agenciava aqueles que desejavam cruzar a fronteira, garantindo a entrada nos Estados Unidos, mediante o pagamento de um valor estipulado, que varia conforme o risco da travessia. A cônsul que ajudou Maria Helena era sua 
Maria Helena afirma que, entre as opções oferecidas, escolheu aquela que lhe parecia mais fácil, ou seja, pagaria U\$S 12.000 para chegar de lancha aos Estados Unidos, como se fosse turista. Decidida a migrar, reuniu as economias que conseguiu com a rescisão de contrato de trabalho $e$, como era conhecida do irmão da cônsul, foi dispensada de deixar uma promissória assinada de sua dívida.

Entrevistadora: Você já tinha passaporte?

Maria Helena: Não, não tinha nada, tive que resolver tudo.

Tirei passaporte....

E: Você tentou tirar o visto no consulado?

MH: Não! Nem tentei.

E: Por que você não tentou?

$\mathrm{MH}$ : Falou que é de Valadares não consegue! Não tem jeito!

E: Como é que você procurou? Como é que você pensou em fazer?

$\mathrm{MH}$ : Eu tenho amigos que levam até cruzar a fronteira. Foi o pai de aluno meu que ofereceu pra levar. Aí eu fui com esse amigo meu, que eu conhecia desde pequena. Nem é ele que leva! Na verdade, ele só... procura as pessoas $e$ entrega pra irmã dele. A irmã dele que é a cabeça. Aí, como eu conhecia, eu já dei aula pro filho dele uns tempos... ela eu também já conhecia um tempo...

E: Ele é daqui de Valadares?

$\mathrm{MH}$ : Ele é! Aí eu fui lá conversar com ele. Tinha que deixar...

E: Uma nota promissória?

MH: É, uma nota promissória, esse tipo de coisa. A maioria do pessoal deixa a casa como garantia, ou alguma coisa assim. Só que, como ele me conhecia, não me pediu nada!

conhecida, moradora da cidade, e mantinha contato com os demais agenciadores dessa rede de tráfico de pessoas. 
A fronteira México-Estados Unidos

Eu tinha dinheiro pra ir... porque eu precisei de dinheiro pra passagem, tive que ir pra São Paulo, pra gastar um pouco no caminho.. Aí eu pedi acerto na escola. Pedi demissão. Perdi o emprego e peguei o dinheiro. Era pouco, mas mesmo assim eu fui.

E: Mas era um dinheiro que você recebeu e que dava pra comprar a passagem..

MH: Dava... dava pra comprar a passagem.

E: Quando você procurou esse rapaz que é daqui de Valadares, ele não era o cônsul não, ele era agenciador?

$\mathrm{MH}$ : Ele era agenciador.

E: O cônsul...

MH: era a irmã dele.

E: A irmã dele mora aqui?

MH: Mora.

E: Ela já morou nos Estados Unidos?

MH: Já! Ela já morou nos Estados Unidos, mas não é casada não!

E: E agora ela vive aqui?

MH: Sim.

$\mathrm{E}$ : E vive de agenciar as pessoas?

MH: É...

$\mathrm{E}: \mathrm{Faz}$ isso?

MH: É.

E: E quanto eles cobraram na época?

$\mathrm{MH}$ : Tem vários preços, porque tem vários caminhos. Se você vai por não sei onde, você paga tanto. Se você vai andar a pé, você paga mais, paga menos. Aí eu falei que eu não andar pelo deserto queria, que eu tinha medo. Ela [referindo-se a cônsul] disse: "Maria Helena então você vai... só que falar uma coisa e chegar lá...é outra".

E: Qual foi o caminho que você escolheu? 
Gláucia de Oliveira Assis

$\mathrm{MH}$ : O caminho que eu escolhi foi ir de lancha. Ia chegar... a gente ia pelo México mesmo, daí do México... que ia, não lembro o lugar da cidade que eu ia... De lá eu ia de lancha, então levei short, óculos... porque a gente ia chegar em Miami como se fosse turista.

E: Por esse pacote qual era o preço?

$\mathrm{MH}$ : Era cobrado 12 mil dólares.

E: E nessa época não se pedia visto pro México ainda?

MH: Não, não pedia... Faltava, faltou um mês daí começaram a pedir o visto!

Maria Helena imagina sua viagem, confia na cônsul $e$, embalada por essa confiança, arrisca-se. No entanto, como mostra seu relato, a tentativa de cruzar a fronteira foi frustrada: ela foi "raptada pelo coiote". Por algum tempo teve sede e não viu água para beber, além de água de torneira, que, segundo ela, era barrenta. Ficou sem comer durante alguns dias e conta que, quando o coiote levava comida, era apenas um pão de fôrma para muitas pessoas que estavam sob "domínio" deles. Passou por provocações dos coiotes, no que tange às relações entre homens e mulheres; menciona, durante a entrevista, a preferência dos mexicanos por mulheres brasileiras e o modo como eles propunham trocas de favores, por exemplo, a possibilidade de melhor higiene pessoal em troca de favores sexuais.

Maria Helena [simulando a cônsul falando com ela], tipo assim, não leva roupa muito decotada, esses negócio assim, porque os mexicanos não é fácil... Eles gostam de mulher brasileira, então... leva umas blusa de malha, umas coisas assim.

(...) Eles entram [os mexicanos] na casa e dá aquelas mexidas com a gente. Só que a gente ficava num quarto jogando baralho, aí eles mandavam os homens sair [homens migrantes], quando eles chegavam e sentavam tudo a nossa volta e daí começavam a perguntar quem tinha namorado, quem não tinha, e começavam com 
A fronteira México-Estados Unidos

gracinha. Quer ficar aqui? Não quer tomar um banho melhor não? Não quer dormir hoje melhor não? Se a gente ficasse com ele a gente come, a gente tem tudo.

Maria Helena e uma amiga valadarense passaram por uma experiência singular junto aos coiotes: elas foram seqüestradas no México pelo próprio coiote e depois compradas por um outro coiote por mais U $\$ 10.000$ cada uma, aumentando a dívida, que era de U\$ 12.000 , para U\$22.000. Após sua "compra" pelo outro coiote, ela realizou a travessia do rio em cima de uma bóia de pneu. Logo após a travessia (já nos Estados Unidos), foi parada por um policial e levada à migração por não portar documentos.

(...) Chegamos na beira do rio, daí ele mandou o primo dele com a gente mesmo, com celular, qualquer coisa vocês ligam pra mim, qualquer coisa. Aí ele [o coiote que a comprou] deu o telefone dele mesmo, deu uns códigos, tipo senha, falou que o que precisasse lá dentro podia procurar porque tinha parente lá.(...) Então a gente chegou lá na beira do rio, era o quê? Umas duas, três horas da tarde... Aî tinha dois coiotes, (...) Aí eles mandaram a gente tirar a roupa pra atravessar, e eles disseram que não, que a gente não ia tirar a roupa. Daí a gente foi atravessar, a gente de roupa, e eles atravessaram pelados. Porque eles dizem que é mais leve pra nadar, que não atrapalha pra nadar. Bom, aí eles deram duas bóias e mandaram a gente encher duas bóias de pneu. Ele colocou no rio, e entrou primeiro. (...) Aí eu fui em cima de uma bóia e minha amiga em cima de outra. E ele foi nadando e empurrando e outro ajudando. Só que como tava com muita correnteza, não vai assim, né? Vai muito descendo... Depois ainda andamos mais uma hora. Aí chegamos num carro e ele entregou a gente. Aí esse carro não tava numa estrada, tava dentro de uma cidade já. (...) Aí a gente entrou dentro do carro, e daí a gente avistou de muito longe alguém, que passou pela gente e era um policial de bicicleta, que fez assim pro cara, daí quando ele olhou pra ver se o cara ia colocar o cinto 
Gláucia de Oliveira Assis

mesmo, ele pediu pra encostar o carro. Daí ele levou todo mundo pra migração e eu fiquei presa mais dois meses lá dentro.

Maria Helena retornou para casa dos pais, em Governador Valadares, após dois meses na prisão. Lá era chamada de Sol, em alusão à personagem da novela "América", e ficou com as roupas cor de laranja - "do mesmo jeito que aparece na TV" juntamente com outras mulheres mexicanas e guatemaltecas que tentaram cruzar a fronteira. Retornou, finalmente, para casa $e$ foi recebida como "heroína": havia faixas e cartazes dizendo "Bemvinda, Sol".

Essa experiência ocorreu antes do retorno da exigência de visto para México, no final de 2005. Depois do retorno do visto, o caminho ficou mais longo, pois os migrantes passam a ir para a Guatemala para cruzar a fronteira e de lá passar pela fronteira do México. Assim fez Laura, esposa de Elton, que já se encontrava nos Estados Unidos que, com a ajuda do primo já estabelecido, conseguiu financiamento para trazer sua esposa para se juntar a ele. Deixaram a filha no Brasil aos cuidados da avó materna. Foi ela quem acompanhou a decisão do filho, que migrou em 2005, antes do retorno de exigência de visto par o México e que migrou também pela fronteira e foi a sogra que viu a nora decidir migrar para ir ao encontro do marido e deixar a filha de cinco anos aos seus cuidados no Brasil.

A travessia foi mais difícil e demorada: Laura cruzou duas fronteiras. Ela que nunca havia saído do Brasil e não se considerava aventureira foi com o tio e um outro rapaz de sua cidade, para a cidade de Flores, na Guatemala, e de lá pegaram um trem para atravessar a fronteira sul da Guatemala. Viajaram num vagão de carga umas 30 pessoas com fome, frio e sem acomodações. Quando chegaram ao México, foram para a fronteira e ficaram uma semana nessa casa próxima à fronteira para atravessar lá onde "tem gente de tudo quanto é lugar". Laura escreveu seu nome na parede e deixou um versículo da Bíblia, 
A fronteira México-Estados Unidos

cada um escreve uma coisa, disse ela, antes de partir para a travessia pelo rio. Atravessaram de bóia e, depois de conseguirem cruzar a fronteira, sempre junto com seu tio, eles foram sendo trocados de caminhão em caminhão até chegaram a Boston. "Ninguém me tocou, cheguei a Boston e fiquei uns cinco dias abobada, não conseguia falar".

O marido, que tinha ficado um mês sem notícias, estava desesperado quando sua mulher chegou. A travessia de Laura custou US\$ 13.000 e eles confiavam em quem tinha escolhido o trajeto, mas não imaginavam que seria tão difícil e arriscado. Quem ajudou na migração foi um vizinho cujo nome a sra. Natalia falou bem baixinho, com medo de que ele tivesse problemas com a polícia. Foi ele quem ajudou os dois a se reencontrarem. Agora, nos Estados Unidos, ambos trabalham $e$ vivem as incertezas de imigrantes indocumentados, não têm documentos para dirigir, evitam sair nos finais de semana de carro, que usam apenas para o trabalho, e não podem voltar ao Brasil a não ser definitivamente, o que pretendem fazer no final de 2009.

\section{Gênero e riscos na fronteira}

Homens e mulheres relatam, a partir de diferentes perspectivas, a travessia. Embora para ambos seja difícil, envolva riscos, ao contar a experiência revelam que cruzar a fronteira é também atravessado por gênero.

Os caminhos, de alguma maneira, são conhecidos. Nos relatos daqueles que conseguiram passar, às vezes, eles dizem que é "exatamente como haviam me contado" ou "igual a travessia da Sol na novela", ou, ainda, que haviam encontrado no caminho, ou seja, no meio do deserto, uma sacola do supermercado de sua cidade de origem. Descobri recentemente um jovem, de 23 anos, que filmou toda a travessia e depois enviou a fita para a mãe. Ainda não consegui ter acesso à fita, mas conversei com a prima que assistiu e comentou que os familiares se reúnem para assistir 
ao DVD, que narra a travessia em todos os seus momentos. Só não aparece o momento derradeiro de cruzar a fronteira $e$, nesse momento, o rapaz que é o sujeito que está sendo filmado apenas fica em silêncio, chora e desliga a câmera. "Aqui é a terra em que o filho chora e a mãe não vê", mas o DVD, quando chega, revela a travessia para os parentes e amigos e mostra o caminho difícil, mas reafirma a possibilidade de emigrar e a coragem do jovem que empreendeu a travessia. A coragem na travessia é reiterada em vários relatos, como o de Celso, que narrava com certo orgulho o fato de ter cruzado a fronteira duas vezes.

Há relatos dissonantes, vozes que se perderam no deserto, pessoas que morreram na travessia, famílias que perderam seus filhos. Não obstante o risco que todos conhecem, homens $e$ mulheres resolvem cruzar o caminho.

Esse foi o caso de Helena, a mulher que ficou presa na fronteira, seqüestrada por coiotes e, depois de cruzar a fronteira, foi presa novamente nos Estados Unidos e deportada para o Brasil. Sua experiência pode ser categorizada como tráfico de migrantes, embora ela mesma relate que não conseguiu perceber esse nó na rede, ou seja, das redes de amigos, parentes e conterrâneos para as redes de tráfico de migrantes. No seu relato, assim como no relato de Laura, não destaca sua coragem na travessia, mas como conseguiu se proteger dos coiotes.

As mulheres não sublinharam, em seus relatos, sua bravura e coragem, mas o modo como conseguiram proteger-se dos riscos. A recomendação explícita, desde o momento em que saem da cidade de destino, é para usarem roupas pouco provocantes a fim de não correrem risco - o maior deles é o estupro ou o abuso por parte dos coiotes. Quando conseguem atravessar, observam que não sofreram nada, que foi difícil, mas que "nada" aconteceu. De qualquer forma, precisam negociar sua identidade de gênero $e$, particularmente, as representações sobre as mulheres brasileiras, tidas como sensuais e liberais.

Assim, à medida que as fronteiras se fecham e a vigilância aumenta, as redes de tráfico de migrantes tornam-se mais 
A fronteira México-Estados Unidos

articuladas e colocam os migrantes em situação de maior risco $e$ vulnerabilidade, embora eles nem sempre se dêem conta da extensão do risco, pois confiam nas pessoas que lhes passaram as informações no ponto de partida, ou seja, na sua cidade de origem.

\section{Considerações finais}

Este artigo procurou analisar as tentativas de cruzar a fronteira do México com os Estados Unidos demonstrando como homens e mulheres narram suas experiências de travessia e de vida no estrangeiro, visando desvelar como percebem as redes de tráfico de migrantes (smuggling) que, muitas vezes, são traduzidas pelos mesmos como, aqueles que ajudam na travessia. Embora nos termos do "Protocolo Adicional à Convenção das Nações Unidas contra o crime organizado transnacional relativo ao tráfico de migrantes por via terrestre, marítima e aérea", assinado pelo governo brasileiro em 2000, o que os emigrantes percebem como ajuda seja considerada crime, $e$ inclusive os próprios migrantes sejam criminalizados, eles não se percebem como criminosos.

A noção de "ajuda", relatada pelos/as migrantes, permite compreender porque, para os migrantes, eles não cometeram crime ao cruzar a fronteira, embora utilizem meios ilegais para fazê-lo. Na sua perspectiva, queriam apenas cruzar a fronteira em busca de trabalho e de uma vida melhor. Os relatos também permitem perceber que as redes sociais, tão importantes para fornecer informações para homens e mulheres emigrantes, são acionadas novamente quando pretendem cruzar a fronteira.

A confiança nos amigos, parentes ou conterrâneos que fornecem as informações sobre como atravessar, quais os riscos, o que evitar e como se comportar, no caso das mulheres, circulam e, num certo sentido, os emigrantes "conhecem" o que poderão encontrar. Entretanto, essa confiança nos conhecidos, amigos e parentes, no contexto do smuggling, escapa ao controle daqueles que ajudaram no ponto inicial dessa rede. A "cônsul" que ajudou 
Maria, embora sua conhecida, não pode evitar seu rapto, assim como, em outros casos, não conseguem ter controle sobre o momento da travessia $e$ os riscos e violências aos quais se submetem esses homens e mulheres em busca do "sonho americano" que, muitas vezes, se transforma em pesadelo: deportações, morte e violência são narrativas do sonho frustrado...

Assim, é nesse jogo de confiança nos agenciadores conhecidos em sua cidade de origem - às vezes vizinhos, ou indicados por algum amigo, ou mesmo parentes - que os migrantes inserem-se nas redes de tráfico de migrantes. Esses emigrantes, em certo sentido, confiam nos agenciadores, no "cônsul" de sua cidade, que os coloca na rede de tráfico de migrantes, na mão de desconhecidos e sobre o qual não tem absoluto controle: quando partem, há garantias de segurança e de chegar aos Estados Unidos, mas o percurso envolve o risco e a imprevisibilidade, fatores característicos do envolvimento das redes internacionais de tráfico de migrantes.

Tornar-se "cidadão do mundo" talvez seja possível para pessoas que "podem" circular livremente, com passaportes carimbados, com vistos dentro do prazo de validade e autorização para trabalhar no exterior, o que ocorre com profissionais muito qualificados ou atletas, mas não com os milhares de trabalhadores indocumentados. Estes se arriscam a chegar aos países de destino na Europa ou nos Estados Unidos como turistas para depois trabalhar ou cruzam fronteiras ilegalmente, como no caso do México.

Nesse sentido, quando se pensa na permeabilidade das fronteiras e na concessão de vistos, constata-se que elas são fluidas para os viajantes considerados "desejados", que preenchem os requisitos de entrada, às vezes, tão subjetivos, como vimos nos casos das recentes deportações de brasileiras na Europa, mas são mais duras e pouco permeáveis para os migrantes, os quais têm de cruzar as fronteiras com seus corpos sexualizados, racializados, marcados por gênero, o que acaba 
A fronteira México-Estados Unidos

contribuindo para o fortalecimento das redes de tráficos de migrantes.

\section{Referências bibliográficas}

Assis, Gláucia de Oliveira. De Criciúma para o mundo: rearranjos familiares e de gênero nas vivências dos novos migrantes brasileiros. Tese de Doutorado em Ciências Sociais, Universidade Estadual de Campinas, 2004, 340p.

. De Criciúma para o mundo os novos fluxos da população brasileira: gênero e rearranjos familiares. In: MARTES, Ana Cristina B. e FLEISCHER, Soraya. (orgs.) Fronteiras cruzadas: etnicidade, gênero $e$ redes sociais. São Paulo, Paz e Terra, 2003, pp.199-230.

Da Segunda Grande Guerra à "guerra contra o terror": uma análise das políticas migratórias no Brasil e nos Estados Unidos. Anais da VI RAM - Reunião de Antropologia do Mercosul. Montevidéu, 2005 (disponível em CD).

BAUMAN, Zygmunt. Turistas e vagabundos. In: Globalização: as conseqüências humanas. Rio de Janeiro, Jorge Zahar Editor, 1999, pp.85-111.

Blanchette, Thaddeus e Silva, Ana Paula da. "Nossa Senhora da Help": sexo, turismo e deslocamento transnacional em Copacabana. Cadernos Pagu (25) Campinas-SP, Núcleo de Estudos de Gênero Pagu/Unicamp, jul/dez 2005, pp.249-281.

CAMPOS, Emerson. Territórios deslizantes: miscelâneas e exibições na cidade contemporânea Criciúma (1980-2002). Tese de Doutorado, Programa de Pós-graduação em História, UFSC, Florianópolis, 2003 (disponível em www.ufsc.br).

Flujos contemporáneos: territorios y traducción cultural entre emigrantes brasileños no documentados en la región fronteriza México-Estados Unidos (1995-2007). Comunicaciones Simposio Nuevos Retos del trasnacionalismo en el estudio de las migraciones. Barcelona, 2008 (http://docsgedime.files.wordpress.com).

CHOMSKY, Noam. 11 de setembro. Rio de Janeiro, Bertrand Brasil, 2001.

KAUfMANN, Helilucia G. Cavalcante. A proteção jurídica conferida às vítimas do tráfico internacional de seres humanos. Monografia de 
conclusão do curso de Direito, Universidade do Oeste de Santa Catarina, São Miguel do Oeste, 2007, 96p.

KEMPADOO, Kamala. Mudando o debate sobre o tráfico de mulheres Cadernos Pagu (25) Campinas-SP, Núcleo de Estudos de Gênero Pagu/Unicamp, jul/dez 2005, pp.55-79.

E DoEzEMA, Jo. (orgs.) Global Sex Workers - Rights,

Resistance, and Redefinition. Nova York/Londres, Routledge, 1998.

LEAL, Maria Lúcia e LEAL, Maria de Fátima. Pesquisa sobre tráfico de mulheres, crianças e adolescentes para fins de exploração sexual comercial no Brasil - PESTRAF: Relatório Nacional. Brasília, CECRIA, 2003.

MARCON VENSON, Anamaria. Prostituição e tráfico de mulheres na rota Brasil-Espanha na perspectiva de profissionais do sexo. Anais do IX Encontro Nacional de História Oral, UNISINOS, São Leopoldo, 22 a 25/04/2008.

MARGOLIS, Máxime. Na virada do milênio a migração de brasileiros para os Estados Unidos. In: MARTES, Cristina B. e FleISCHER, Soraya. (orgs.) Fronteiras Cruzadas: etnicidade, gênero e redes sociais. São Paulo, Paz e Terra, 2003.

MERIZ, Gisele. Entre o Brasil e os Estados Unidos - a fronteira: uma análise das deportações na Fronteira do México no início do século XXI. Trabalho de conclusão de curso, História, Universidade do Estado de Santa Catarina, 2007.

NETO, Helion Póvoa. A criminalização das migrações na nova ordem internacional. In: NETO, Helion Póvoa e FERREIRA, Ademir Pacelli (org). Cruzando fronteiras disciplinares: um panorama dos estudos migratórios. Rio de Janeiro, Renan, 2005, p.297-309.

PISCITELLI, Adriana. Brasileiras na indústria transnacional do sexo. Nuevo Mundo Mundos Nuevos, Debates, 2007 (http://nuevomundo.revues. org//index3744.html, acesso em 15/05/2008).

REIS, Rossana Rocha. Construindo fronteiras: políticas de imigração na França e nos Estados Unidos (1980-1998). Tese de Doutorado em Ciência Política, Faculdade de Filosofia, Letras e Ciências Humanas, Universidade de São Paulo, 2003. 
A fronteira México-Estados Unidos

SANTOS, Gislene. Estado redes sociais e fronteira: a migração do sul catarinense para os Estados Unidos. Tese de Doutorado em Geografia, Universidade Federal de Santa Catarina, 2007.

Catarinenses na fronteira México Estados Unidos. Travessia. Revista Migrante, ano XIX, n 55, maio/agosto 2006, pp.23-31.

SECRETARIA NACIONAL DE JUSTIÇA DO MINISTÉRIO DA JUSTIÇA/OIT. Tráfico internacional de pessoas e tráfico de migrantes entre deportados(as) e não admitidos(as) que regressam ao Brasil via o aeroporto internacional de São Paulo. Brasilia, 2007 (Coord. técnica de Adriana Piscitelli), Relatório disponível em www.minsiteriodajustica.br.

SIQUEIRA, Sueli. Migrantes e empreendedorismo na Microrregião de Governador Valadares: sonhos e frustrações no retorno. Tese de Doutorado em Sociologia e Política, Universidade Federal de Minas Gerais, 2006.

YAler-Loher, Stephen, PAPADEMETIOU, Demetrius G. E COOPER, Betsy. Secure borders, open doors: visa procedures post-setember 11 era. Migraton Police Institute, 2005. (www. migrationpolicy.org/pubs/visa_report.pdf, , acesso em 20/05/ 2008).

YUDICE, George. O lugar da cultura no contexto pós onze de setembro. Revista Crítica de Ciências Sociais, Coimbra-Portugal, Editora do Centro de Estudos Sociais, out/2002, pp.175-187. 